\title{
Interface Control and Temperature Dependence of Electrical Conductivity of Carbon Black Filled Polymer Blend
}

\author{
Chifei Wu, Shigeo Asai, and Masao Sumita \\ Depatment of Organic and Polymeric Materials, Tokyo Institute of Technology \\ Ookayama, Meguro-ku, Tokyo, 152 Japan
}

\begin{abstract}
The effect of the oxidation treatment of carbon black(CB) on its distribution state in the polymer blends was examined by scanning electron microscopy. This treatment lends to a transfer of $\mathrm{CB}$ particles from one phase to another of the polymer blend. This exchange of filler rich phase influences the positive temperature coefficient (PTC) property of the polymer blend filled with CB. It was concluded that PTC property of a polymer blend filled with $\mathrm{CB}$ is decided by the distribution state of fillers in the polymer blend, the thermal expansion properties of each component and the blend ratio.
\end{abstract}

\section{INTRODUCTION}

In the matrix of polymer blends which are incompatible with each other, added filler distributes unevenly to each component of a polymer blend $[1-7]$. This uneven distribution of filler in a polymer blend matrix is mainly due to the difference in affinity of the filler to each com. ponent of the polymer blend $[5-7]$. Therefore, if this affinity which is controlled by the oxidation treatment of fillers $[7,8]$ can be changed, the uneven distribution of fillers will be controlled. In this paper, we discuss the effect of the oxidation treatment of $\mathrm{CB}$ on the distribu. tion state of $\mathrm{CB}$ particles in the matrix polymer, and the influence of this change on the temperature dependence of electrical conductivity of filled polymer blends.

\section{EXPERITMENTAL}

\subsection{Composite Sample Preparation}

Two kinds of polymers, i.e., isotactic polypropylene (PP) (Shoaromer MA210; Showa Denko Co.) and poly (methyl methacrylate) (PMMA) (MF; Mitsubishi Rayon Co.) were used as polymer samples. Carbon black (Seast 300. low structure, $27 \mathrm{~nm}$ in diameter Tokai Carbon Co.) was used as a filler. In order to vary the surface free energy of the filler. Seast 300 was oxidized for $3 \mathrm{~h}$ in $50 \%$ boiling nitric acid. $\mathrm{CBO}$ and $\mathrm{CB} 50$ represent unoxi. dized and oxidized $\mathrm{CB}$, respectively. Polymers were first blended and kneaded by a mixing roller for $5 \mathrm{~min}$, and the filler was added to the kneaded mixtures and kneaded for $10 \mathrm{~min}$. The volume fractions of each compo-

Table 1 Composition Ratio (vol\%) of Carbon Black Filled Polymer Blends

\begin{tabular}{ccccc}
\hline PP & PMMA & Unoxidized CB & Oxidzed CB & Blend ratio \\
\hline 92 & & 8 & & \\
69 & 23 & 8 & & $75 / 25$ \\
46 & 46 & 8 & & $50 / 50$ \\
23 & 69 & 8 & & $25 / 75$ \\
& 90 & 10 & 15 & \\
85 & & & 15 & \\
68 & 17 & & 15 & $80 / 20$ \\
59.5 & 25.5 & & 15 & $70 / 30$ \\
51 & 34 & & 15 & $60 / 40$ \\
21.25 & 63.75 & & 18 & $25 / 75$ \\
& 82 & &
\end{tabular}


nent are listed in Table 1 , and the kneading temperature was $190^{\circ} \mathrm{C}$. Prior to mixing, the polymers were dried at $50{ }^{\circ} \mathrm{C}$ for $12 \mathrm{~h}$ under vacuum, and the $\mathrm{CB}$ was dried at $105^{\circ} \mathrm{C}$ for $1 \mathrm{~h}$. Films of $0.8 \mathrm{~mm}$ thickness were com. pression-molded from the polymer blend $\mathrm{CB}$ mixtures at $190{ }^{\circ} \mathrm{C}$ for $15 \mathrm{~min}$ under a pressure of $180 \mathrm{~kg} . \mathrm{cm}^{-2}$, followed by quenching into ice water.

\subsection{Scanning Electron Microscopy}

A section of the composite specimen was prepared by braking the specimen in liquid nitrogen. Then the fracture surface which has etched with Eiko IB-3 was coated with gold for SEM observation. SEM photographs were taken with a Nippon Electron JEM-T-220 under the following conditions: working distance $5 \mathrm{~mm}$, tilting angle $15^{\circ}$, applied voltage 15 and $20 \mathrm{kV}$.

\subsection{Electrical Conductivity Measurement}

The electrical conductivity was measured through the vertical thickness of the composite films, in heating. The heating rate was $1^{\circ} \mathrm{C} / \mathrm{min}$. Sillver paste was used to ensure good contact of the sample surface with the elec. trodes of the conduction tester.

\section{RESULTS AND DISCUSSION}

\subsection{Dispersion of CB Particles in Polymer Matrix}

From the calculation listed in Table 2, it can be seen that, the interfacial free energy of $\mathrm{PP} / \mathrm{CB} 0$ is smaller than that of $\mathrm{PMMA} / \mathrm{CBO}$; the interfacial free energy of PMMA/CB50 is smaller than that of PP/CB50. Thus, it is predicted that $\mathrm{CB}$ particles transfer from a phase PP to another phase PMMA by the oxidition treatment of CB. Figs. 1 (a), (b) and (c) are SEM photographs of $6 \%$ volume CBO filled PP/PMMA (75/25, 50/50, 25/75) blends, respectively. Fig. 2 (a) and (b) are SEM photographs of $6 \%$ volume CB50 filled PP/PMMA (75/25, $25 / 75)$ blends. Certainly, oxidation of $C B$ particles changed the filler distribution type in PP/PMMA blends: CB50 particles ware predominantly dispersed in the PMMA phase, while $\mathrm{CB} 0$ particles were mainly concentrated at the interface of the two polymers.

\subsection{Temperature Dependence of Electrical Conductivity of the Polymer Blend Filled with $\mathrm{CB}$}

Conducting particles, such as $\mathrm{CB}$ filled insulating rubber and plastics, have found extensive application in the various industries. A problem of great importance is the variation of the electrical conductivity of these composites with temperature. This effect was termed the posi-
Table 2 Interfacial Free Energy $\gamma_{12}\left(\mathrm{~mJ} / \mathrm{m}^{2}\right)$

\begin{tabular}{ccc}
\hline \multirow{2}{*}{ 1-Polymer } & \multicolumn{2}{c}{2 -Filler } \\
\cline { 2 - 3 } & $\mathrm{CB}$ & Oxidized CB \\
\hline PP & 4.1 & 6.7 \\
PMMA & 8.0 & 4.9 \\
\hline
\end{tabular}

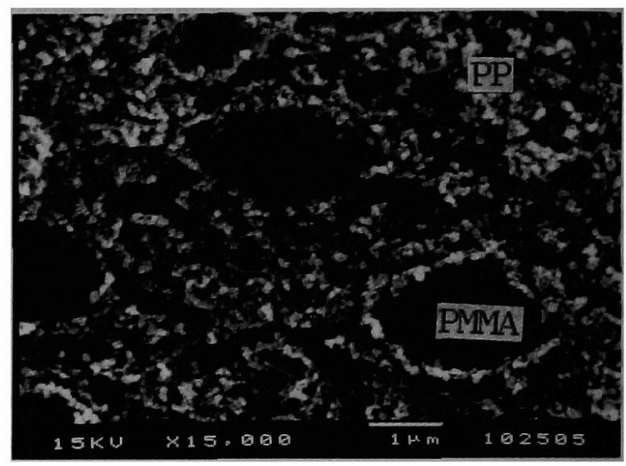

(a)

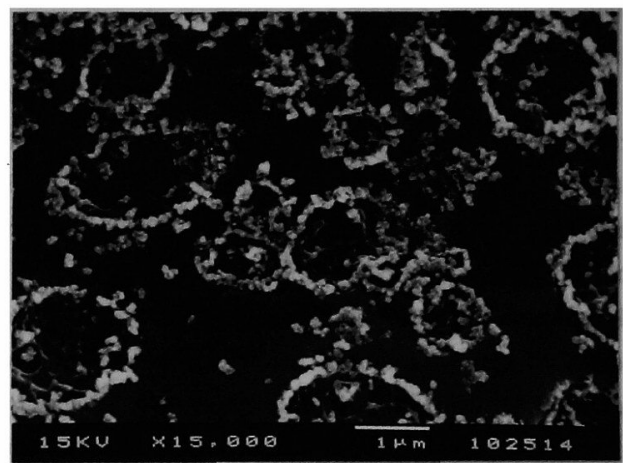

(b)

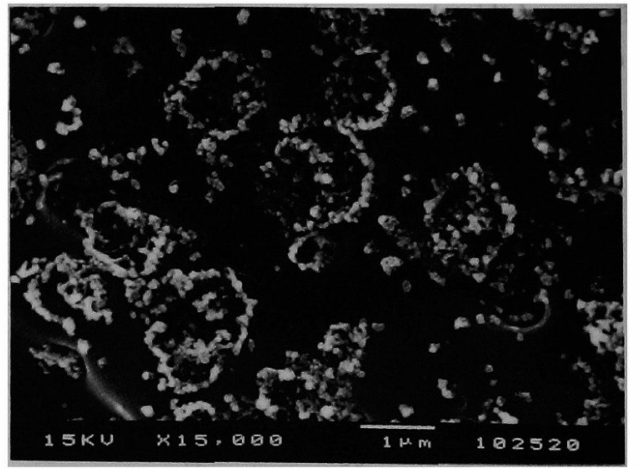

(c)

Fig. 1 SEM photographs of $6 \%$ volume CB filled PP/ PMMA blends; blend ratio: (a) $75 / 25$, (b) $50 / 50$, (c) $25 /$ 75. 


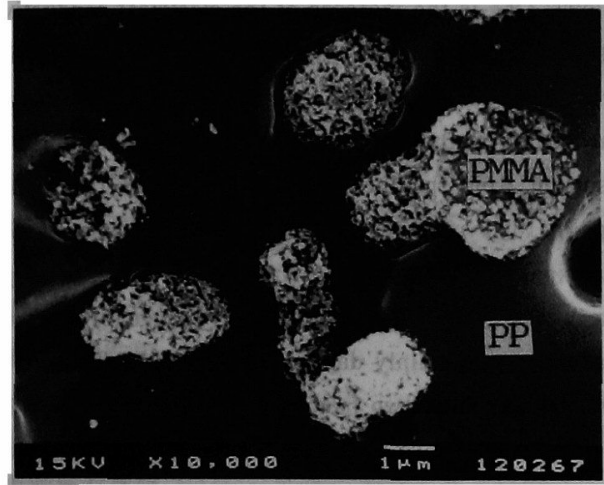

(a)

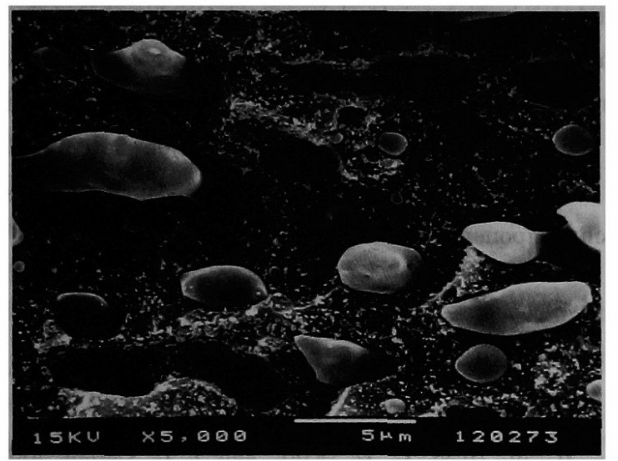

(b)

Fig. 2 SEM photographs of $6 \%$ volume oxidized $C B$ filled PP/PMMA blends; blend ratio: (a) $75 / 25$, (b) $25 / 75$.

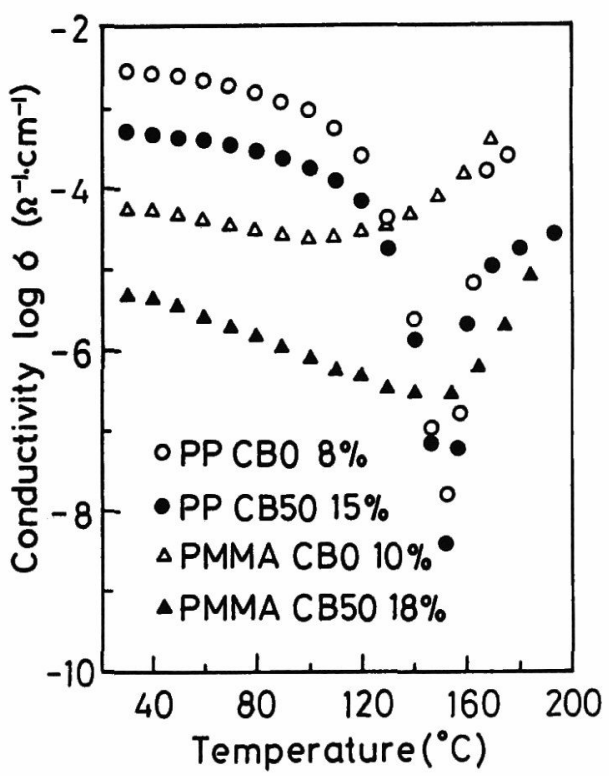

Fig. 3 Temperature dependence of electrical conductiv. ity for PP, PMMA filled with $\mathrm{CB}$, oxidized $\mathrm{CB}$ in heating.

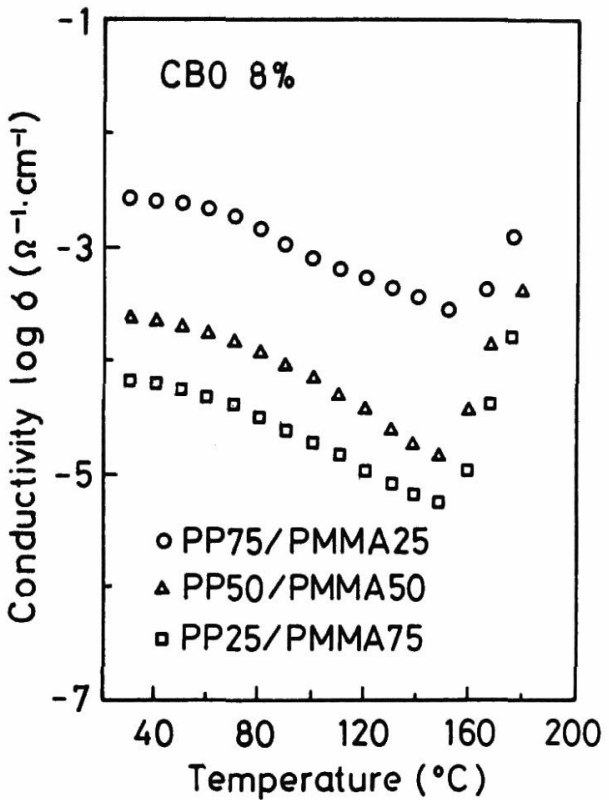

Fig. 4 Temperature dependence of electrical conductivity for PP/PMMA blends filled with $\mathrm{CB}$ in heating.

tive temperature coefficient or PTC.

Fig. 3 shows the temperature dependence of the electrical conductivity for $\mathrm{CB}$ filled PP. PMMA in heating. The electrical conductivity of crystalline polymer PP filled with $\mathrm{CB}$ shows a large PTC property below its melting temperature $\left(160^{\circ} \mathrm{C}\right)$, while that of amorphous poly. mer PMMA filled with $C B$ does not show such a large change. This PTC property is due to the increase of interparticle gaps allowed electron tunneling, created by the thermal expansion of the matrix accompanied with melting of crystalline phase, and can be correlated with the crystallinity of the matrix polymer and the filler content. In the earlier work $[9]$. We have shed light on the electrical conduction mechanism and its temperature dependence of single polymer filled wlth $\mathrm{CB}$.

Fig. 4 shows the variation of the electrical conductivity of PP/PMMA filled with $\mathrm{CB} 0$ for various blend ratio with temperature. It was found that the peak of the electrical conductivity during heating is the same as $T_{m}$ of filler rich phase PP, while their extent of PTC does not change so much by their blend ratio, which is different from HDPE/PP and HDPE/PMMA filled with CBO [10]. These regults on the fillers were mainly concentrated at the interface of the domain of PP phase, as can be seen 


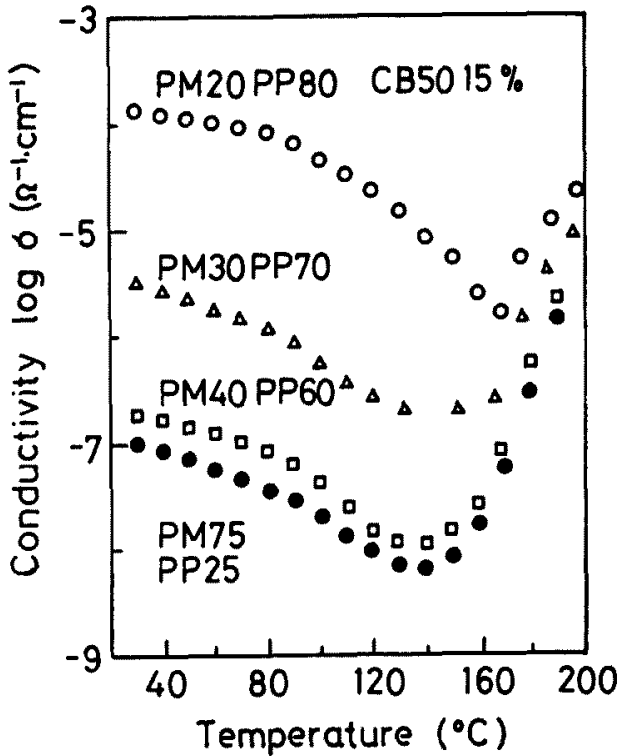

Fig. 5 Temperature dependence of electrical conducivity for PP/PMMA blends filled with oxidized $C B$ in heating.

in Fig. 1.

Fig. 5 exhibits the variation of the electrical conductivity of PP/PMMA filled with CB50 for various blend ratio with temperature. The PTC properties as a function of the blend ratio of these composites were found as follows: for 75-40\% PMMA (filler rich phase), the electrical conductivity-temperature curves are practically same with that of single polymer PMMA filled with CB50; for $30 \%$ PMMA, the electrical conductivity does not change during $140-170{ }^{\circ} \mathrm{C}$ range; for $20 \%$ PMMA, the variation of the electrical conductivity is larger than that of single polymer PMMA, and their peak is shifted to $170^{\circ} \mathrm{C}$. It should be noted that, as was found in our previous paper [5], the electrical conductivity of $\mathrm{CB}$ filled polymer blends is determined by two factors: one is the concentration of filler in the filler rich phase, and another is structural continuity of this phase. Therefore, the change of the electrical conductivity with temperature of $\mathrm{PP} /$ PMMA filled with CB50 is determined by two factors as follows: One is the increase of the electrical conductivity resulting from the concentration of the particles in filler rich phase PMMA, which is related to the blend ratio. The second is the decrease of the electrical conductivity resulting from the increase of inter conductive domain gaps of filler rich phase PMMA accompanied with ther. mal expansion of another component PP (crystalline pol. ymer). For $75 \sim 45 \%$ PMMA, the change of electrical conductivity is mainly determined by the first factor; for $30 \%$ PMMA, these two factors were balanced during 140 $\sim 170^{\circ} \mathrm{C}$ range, so that ther electrical conductivity is fixed. Further, for 20\% PMMA, the change of electrical conductivity is mainly determined by the second factor. Therefore, in addition to our previous result [10], it was concluded that the PTC property of a polymer blend filled with $C B$ is decided by the distribution state of fillers in the polymer blend, the thermal expansion prperties of each component and the blend ratio.

\section{REFERENCES}

1. M. H. Walters and S. N. Keyte, Trans. Inst. I. R. I, 38, 40 (1962).

2. W. M. Hess, C. E. Scott, and J. E. Callan, Rubber Chem. Technol., 40, 371 (1967).

3. G. R. Cotten and L. J. Murphy, Rubber Chem. Technol., 61, 609 (1989).

4. M. E. Fowler, H. Keskkula, and D. R. Paul, J. Appl. Polym. Sci., 37, 225 (1989).

5. M. Sumita, K. Sakata, S. Asai, and K. Miyasaka, Polym. Bull., 25, 265 (1991).

6. M. Sumita, K. Sakata, S. Asai, K. Miyasaka, and H. Nakagawa, Sen'i Gakkaishi, 47, 384 (1991).

7. S. Asai, K. Sakata, M. Sumita, and K. Miyasaka, Polym. J., 24, 415 (1992).

8. C. Wu, S. Asai, M. Sumita, and K. Miyasaka, Sen' $i$ Gakkaishi, 48, 389 (1992).

9. C. Wu, K. Suzuki, S. Asai, M. Sumita, and K. Miyasaka, Tanso, 153, 149 (1992).

10. C. Wu, S. Asai, M. Sumita, and K. Miyasaka, Nippon Gomu Kyokaishi, 65, 35 (1992). 